\title{
Effectiveness of icatibant for treatment of hereditary angioedema attacks is not affected by body weight: findings from the lcatibant Outcome Survey, a cohort observational study
}

\author{
Teresa Caballero ${ }^{1,8^{*}}$, Andrea Zanichelli ${ }^{2}$, Werner Aberer ${ }^{3}$, Marcus Maurer ${ }^{4}$, Hilary J. Longhurst ${ }^{5,9}$, \\ Laurence Bouillet ${ }^{6}$ and Irmgard Andresen ${ }^{7}$ on behalf of the IOS Study Group
}

\begin{abstract}
Background: Icatibant is a bradykinin B2-receptor antagonist used for the treatment of hereditary angioedema attacks resulting from C1-inhibitor deficiency. Treatment is not adjusted by body weight however the impact of body mass index (BMI) on the effectiveness of icatibant is not documented in the literature. We examined disease characteristics and icatibant treatment effectiveness in patients stratified by BMI in the Icatibant Outcome Survey, an ongoing, international, observational study monitoring the real-world safety and effectiveness of icatibant.

Methods: Attack and treatment characteristics as well as outcomes following treatment with icatibant were compared among patients with underweight, normal, overweight, and obese BMI.

Results: Data from 2697 icatibant-treated attacks in 342 patients $(3.5,44.7,34.8$, and 17.0\% patients of underweight, normal, overweight, and obese BMI, respectively) were analyzed. There was no significant difference in the frequency and severity of attacks across BMI groups, although obese patients tended to have more attacks of high severity. There was no impact of BMI on the frequency of laryngeal attacks, but patients with normal BMI had fewer cutaneous attacks and more abdominal attacks. Most attacks (71.9-83.8\%) were treated with a single icatibant injection without the need for rescue with plasma-derived C1-inhibitor ( $\mathrm{pdC1}$ - INH), regardless of BMI. Patients with obese BMI used pdC1-INH as rescue treatment more often ( $P<0.0001 ; P=0.0232$ excluding 2 outliers) and treated attacks earlier than patients with normal $\mathrm{BMI}(P=0.007)$. Furthermore, time to resolution and duration of attack were shorter for patients with high $\mathrm{BMI}(\mathrm{P}<0.001$ for overweight and $\mathrm{P}<0.05$ for obese versus normal).
\end{abstract}

Conclusion: Overall, icatibant was comparatively effective in treating attacks in patients across all BMl groups. Trial registration NCT01034969.

Keywords: Hereditary angioedema, Icatibant, Bradykinin, Body mass index

\section{Background}

Hereditary angioedema due to C1-inhibitor (C1-INH) deficiency (C1-INH-HAE) is a genetic disease, affecting one in 50,000 [1] people, with symptoms such as localized cutaneous swelling, abdominal pain, and laryngeal

\footnotetext{
*Correspondence: mteresa.caballero@idipaz.es

${ }^{8}$ Servicio de Alergia, Hospital Universitario La Paz, Paseo de la Castellana 261, 28046 Madrid, Spain

Full list of author information is available at the end of the article
}

edema [2]. C1-INH-HAE is caused by mutations in the SERPING1 gene, leading to C1-INH deficiency and subsequently elevated levels of bradykinin, the mediator of increased vascular permeability during attacks $[1,3]$.

Icatibant (Firazyr ${ }^{\circledR}$; Shire, Zug, Switzerland) is a subcutaneously administered bradykinin B2 receptor antagonist that has demonstrated efficacy and safety for the treatment of acute attacks of C1-INH-HAE $[4,5]$. The approved dose of icatibant in patients $\geq 18$ years of age 
is $30 \mathrm{mg}$, and is based on clinical studies using a dose of $0.4 \mathrm{mg} / \mathrm{kg}$ body weight. Clinical trials did not show an impact of body weight on the safety and efficacy of icatibant, and dosing is not adjusted by body weight. However, the effect of body weight on treatment outcomes has not been evaluated in the real-world setting. Body weight can have an impact on the pharmacokinetics and pharmacodynamics of a drug and, subsequently, its effectiveness. In addition, the relationship between body weight and the characteristics of C1-INH-HAE attacks is not known.

The Icatibant Outcome Survey (IOS; NCT01034969) is an ongoing international observational study that monitors the safety and effectiveness of treatment with icatibant. In this analysis, the relationship between body mass index (BMI), attack characteristics, and icatibant treatment outcomes in patients with C1-INH-HAE type I and type II receiving icatibant was investigated in the realworld setting.

\section{Methods Study design}

Details on the design and conduct of IOS are described elsewhere [6]. Patients were enrolled from 51 sites in 11 countries: Brazil, Israel, and across Europe. In this analysis, data from icatibant-treated patients with C1-INH-HAE type I or II were obtained from patients who entered the study between July 2009 and February 2016. Patients were divided into groups according to their BMI at baseline (i.e., before enrollment): underweight $\left(<18.5 \mathrm{~kg} / \mathrm{m}^{2}\right)$, normal $\left(18.5\right.$ to $\left.<25.0 \mathrm{~kg} / \mathrm{m}^{2}\right)$, overweight $\left(25.0\right.$ to $\left.<30.0 \mathrm{~kg} / \mathrm{m}^{2}\right)$, or obese $\left(\geq 30 \mathrm{~kg} / \mathrm{m}^{2}\right)$. Details regarding the characteristics of icatibant-treated C1-INH-HAE attacks and the use of any concomitant or rescue medications, including $\mathrm{C} 1-\mathrm{INH}$, were collected via physician-completed electronic forms at routine visits (recommended every 6 months). Patients were educated by their HAE specialist to report attack severity based on the extent of interference with daily activities. Attack severity was classified as: very mild (very mild interference with daily activities); mild (mild interference with daily activities); moderate (moderate interference with daily activities and no other countermeasures required); severe (severe interference with daily activities and with or without other countermeasures); or very severe (very severe interference with daily activities and other countermeasures required).

\section{Statistical analysis}

Due to the small number of patients and attacks in the underweight BMI group, statistical comparisons of BMI groups did not include the underweight category, and the results of the underweight BMI group are only summarized descriptively. Statistical testing was considered exploratory in this observational study and no adjustment for multiplicity was performed. There was no imputation of data from patients who discontinued from the study.

Attack rate and duration of untreated attacks were both compared using the Kruskal-Wallis test. Attack severity, attack site, and the use of plasma-derived C1-INH as a rescue medication in the normal, overweight, and obese BMI groups were compared using a generalized linear model of repeated measures (PROC GLIMMIX; SAS Institute Inc., Cary, NC, USA).

Treatment outcomes included time to treatment (time from attack onset to icatibant injection), time to resolution (time from icatibant injection to complete symptom resolution), and attack duration (time from attack onset to complete resolution of symptoms). A mixed-model analysis of repeated measures (PROC MIXED; SAS Institute Inc.) was used to compare mean time to treatment, time to resolution, and duration of attack data for patients in the BMI groups using base-10 log-transformed time data (h). The impact of BMI along with sex, age (i.e., factors that influence BMI), and other patient and attack characteristics on treatment outcomes were analyzed using a generalized linear model of repeated measures with PROC GENMOD (SAS Institute Inc.). A multivariate model was built using a backward selection process, which incorporated variables from the univariate model with $P$ values $<0.20$ and removed factors with the highest $\mathrm{P}$ values until only significant factors remained $(\mathrm{P} \leq 0.05)$. Odds ratios $(\mathrm{ORs})$ and corresponding $95 \%$ confidence intervals were estimated.

\section{Results}

\section{Patient characteristics}

The analysis included data from 2697 icatibant-treated attacks reported by 342 patients with C1-INH-HAE for whom baseline BMI data were available. Of the 342 patients, 12 (3.5\%), 153 (44.7\%), 119 (34.8\%), and 58 (17.0\%) had an underweight, normal, overweight, and obese BMI, respectively (Table 1). There was a comparable distribution of males and females among patients with overweight or obese BMI, but most patients with normal or underweight BMI were female. Almost half $(\mathrm{n}=169 ; 49.4 \%)$ of the patients were using long-term prophylaxis. There was no difference among the normal, overweight, and obese BMI groups in the type of longterm prophylaxis therapy used.

\section{Attack characteristics}

Among the normal, overweight, and obese BMI groups, there was no difference in the mean attack frequency per patient during enrollment $(\mathrm{P}=0.469)$. There were 
Table 1 Patient demographics and number of icatibant-treated attacks

\begin{tabular}{|c|c|c|c|c|}
\hline Characteristic & Underweight BMI & Normal BMI & Overweight BMI & Obese BMI \\
\hline Patients, n (\%) & $12(3.5)$ & $153(44.7)$ & $119(34.8)$ & $58(17.0)$ \\
\hline \multicolumn{5}{|l|}{$\mathrm{BMI}\left(\mathrm{kg} / \mathrm{m}^{2}\right)^{\mathrm{a}}$} \\
\hline Mean \pm SD & $18.0 \pm 0.5$ & $22.2 \pm 1.8$ & $26.9 \pm 1.3$ & $34.5 \pm 4.1$ \\
\hline Median (range) & $18.1(16.7-18.4)$ & $22.4(18.7-25.0)$ & $26.6(25.0-29.8)$ & $33.3(30.0-46.7)$ \\
\hline \multicolumn{5}{|l|}{ Sex, n (\%) } \\
\hline Female & $11(91.7)$ & $105(68.6)$ & $60(50.4)$ & $33(56.9)$ \\
\hline Male & $1(8.3)$ & $48(31.4)$ & $59(49.6)$ & $25(43.1)$ \\
\hline \multicolumn{5}{|l|}{ Age at enrollment (years), n (\%) } \\
\hline$\geq 12$ to $<18$ & $1(8.3)$ & $2(1.3)$ & $1(0.8)$ & 0 \\
\hline$\geq 18$ to $<30$ & $8(66.7)$ & $53(34.6)$ & $24(20.2)$ & $10(17.2)$ \\
\hline$\geq 30$ to $<50$ & $1(8.3)$ & $66(43.1)$ & $52(43.7)$ & $27(46.6)$ \\
\hline$\geq 50$ to $<65$ & $1(8.3)$ & $27(17.6)$ & $30(25.2)$ & $16(27.6)$ \\
\hline$\geq 65$ & $1(8.3)$ & $5(3.3)$ & $12(10.1)$ & $5(8.6)$ \\
\hline \multicolumn{5}{|l|}{ Country, n (\%) } \\
\hline Austria & 0 & $6(3.9)$ & $3(2.5)$ & 0 \\
\hline Brazil & 0 & $6(3.9)$ & $7(5.9)$ & $3(5.2)$ \\
\hline Denmark & 0 & 0 & $1(0.8)$ & $2(3.4)$ \\
\hline France & $2(16.7)$ & $45(29.4)$ & $21(17.6)$ & $8(13.8)$ \\
\hline Germany & $2(16.7)$ & $16(10.5)$ & $16(13.4)$ & $12(20.7)$ \\
\hline Greece & 0 & $3(2.0)$ & $3(2.5)$ & $1(1.7)$ \\
\hline Israel & $2(16.7)$ & $20(13.1)$ & $15(12.6)$ & $6(10.3)$ \\
\hline Italy & $1(8.3)$ & $18(11.8)$ & $14(11.8)$ & $4(6.9)$ \\
\hline Spain & $4(33.3)$ & $20(13.1)$ & $22(18.5)$ & $8(13.8)$ \\
\hline Sweden & 0 & 0 & $1(0.8)$ & 0 \\
\hline United Kingdom & $1(8.3)$ & $19(12.4)$ & $16(13.4)$ & $14(24.1)$ \\
\hline \multicolumn{5}{|l|}{ Ongoing long-term prophylaxis, n (\%) } \\
\hline$n$ & 3 & 75 & 58 & 33 \\
\hline $\mathrm{C} 1-\mathrm{INH} \mathrm{H}^{\mathrm{b}}$ & 0 & $11(14.7)$ & $11(19.0)$ & $4(12.1)$ \\
\hline Attenuated androgens ${ }^{\mathrm{b}}$ & 0 & $47(62.7)$ & $44(75.9)$ & $24(72.7)$ \\
\hline Tranexamic acid ${ }^{b}$ & $2(66.7)$ & $24(32.0)$ & $9(15.5)$ & $11(33.3)$ \\
\hline Other ${ }^{b}$ & $1(33.3)$ & $8(10.7)$ & $4(6.9)$ & $3(9.1)$ \\
\hline No. of icatibant-treated attacks during enrollment & 104 & 1314 & 829 & 450 \\
\hline \multicolumn{5}{|l|}{ No. of icatibant-treated attacks per patient ${ }^{c}$} \\
\hline Mean \pm SD & $8.7 \pm 13.5$ & $8.6 \pm 14.8$ & $7.0 \pm 11.3$ & $7.8 \pm 10.8$ \\
\hline Median (range) & $4.0(1-47)$ & $4.0(1-101)$ & $3.0(1-83)$ & $3.5(1-57)$ \\
\hline
\end{tabular}

$B M I$ body mass index; C1-INH C1-inhibitor; SD standard deviation

a At study entry

b Percentage calculated from number of patients using long-term prophylaxis at study entry and/or during enrollment

c Attack rate during enrollment. $\mathrm{P}=0.469$ comparing the normal, overweight, and obese categories. The underweight category was excluded from the comparison due to small sample size. Two patients (one normal BMI, one obese BMI) were found to be outliers because of an abnormally high rate of reinjections and rescue medication use. When their data are excluded, mean \pm SD for normal $=8.4 \pm 14.6$ attacks/patient and for obese $=6.9 \pm 8.6$ attacks/patient (Additional file $1:$ Table $S 1$ )

more attacks classified as very severe in patients with obese BMI (25.9\%) than in patients with normal (15.4\%) or overweight (9.6\%) BMI (Fig. 1); however, there were no statistically significant differences in attack severity within any of the groups $(\mathrm{P}>0.1$ comparing very mild/ mild/moderate versus severe/very severe attacks).
There were some significant differences in attack site frequency among the BMI groups: patients with normal BMI had fewer attacks affecting the skin $(\mathrm{P}=0.020)$ and more attacks affecting the abdomen $(\mathrm{P}=0.003$; Fig. 2$)$. There was no impact of BMI on the frequency of attacks affecting the larynx $(\mathrm{P}=0.282)$. 


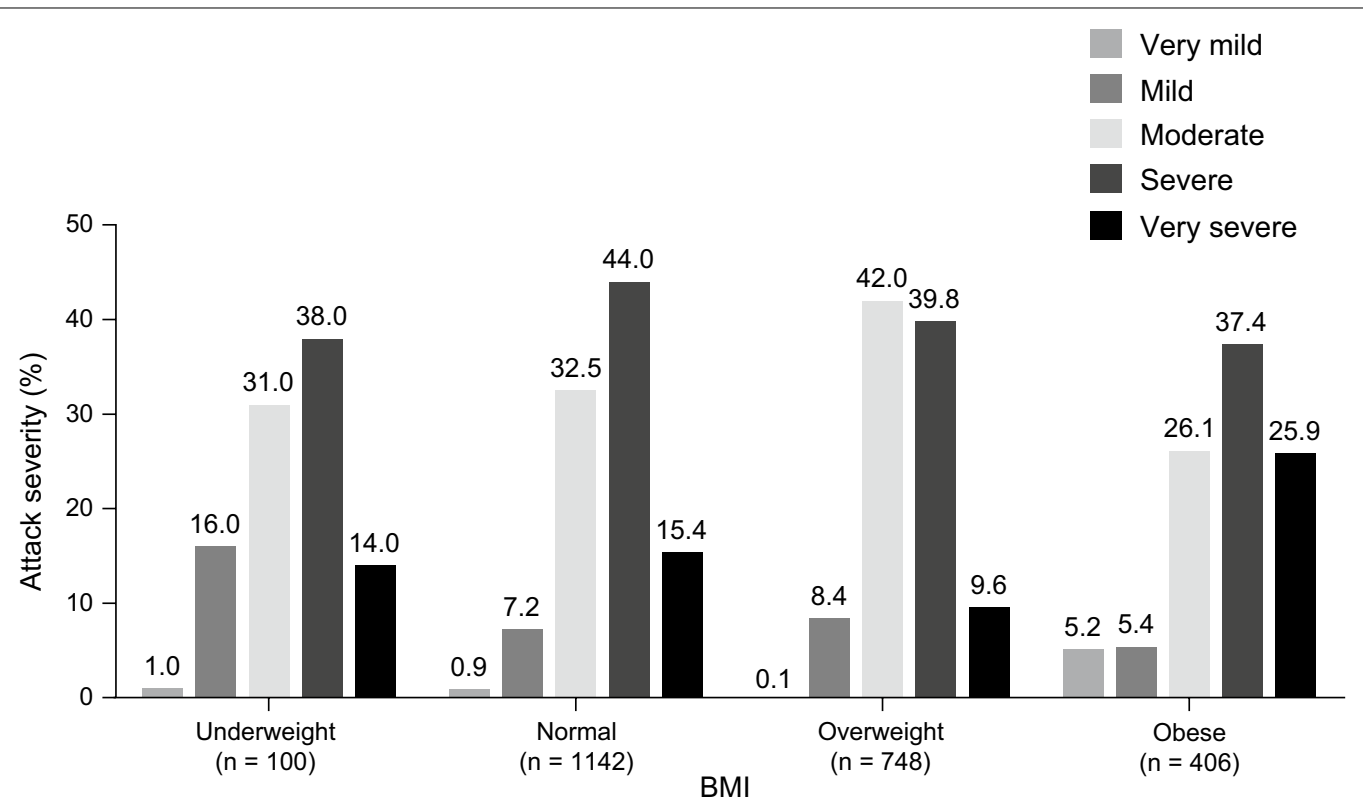

Fig. 1 Severity of icatibant-treated attacks by body mass index (BMI). P values comparing severity of attacks (very mild/mild/moderate versus severe/very severe): $P=0.136$ for normal versus overweight; $P=0.627$ for normal versus obese; $P=0.109$ for overweight versus obese. Results excluding data from the two reinjection outliers are presented in Additional file 1: Figure S1. $n=$ number of attacks. Very mild $=$ very mild interference with daily activities; mild = mild interference with daily activities; moderate= moderate interference with daily activities and no other countermeasures required; severe = severe interference with daily activities and with or without other countermeasures; very severe $=$ very severe interference with daily activities and other countermeasures required

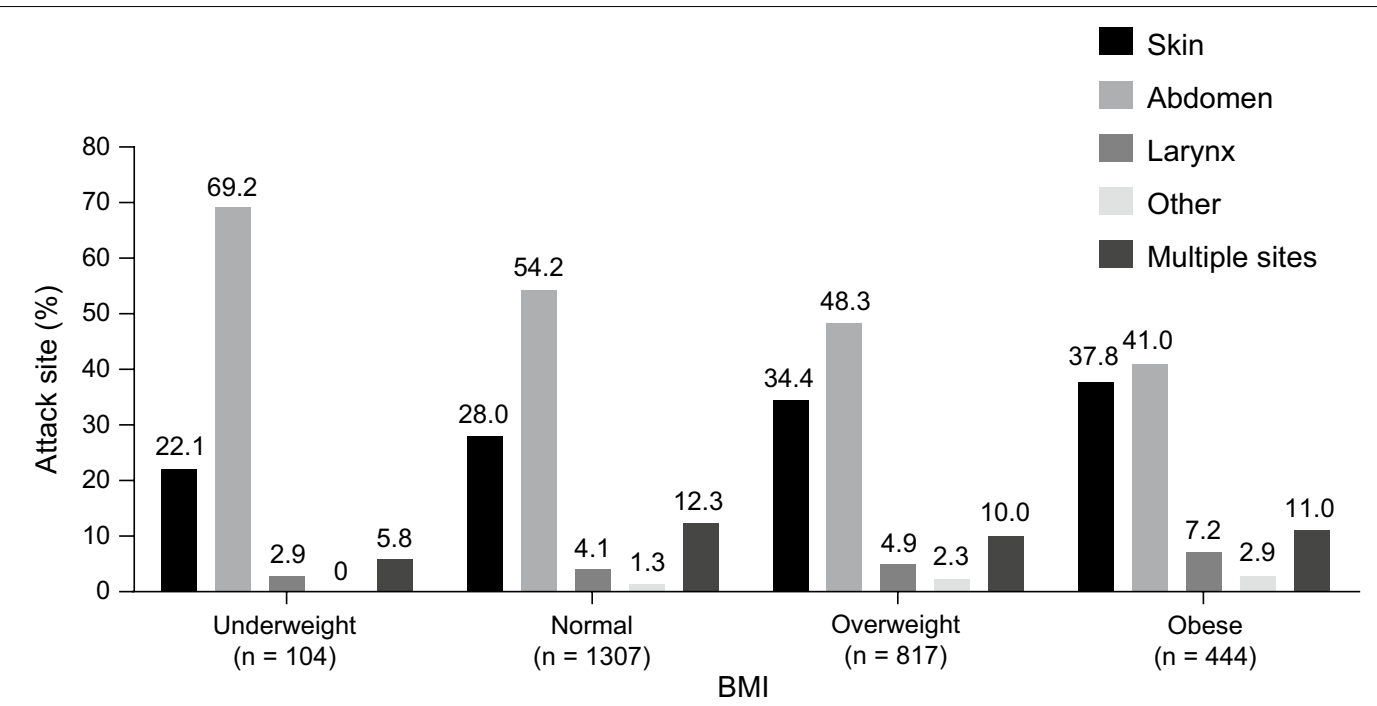

Fig. 2 Site of icatibant-treated attacks by body mass index (BMI). P values comparing frequency of attacks between patients with normal/overweight/obese $B M I: P=0.020$ for skin attacks; $P=0.003$ for abdominal attacks; $P=0.282$ for laryngeal attacks; $P=0.108$ for attacks affecting other organs. Results excluding data from the two reinjection outliers are presented in Additional file 1: Figure $\mathrm{S} 2 . \mathrm{n}=$ number of attacks

The IOS database also captured some information on attacks that were untreated. A total of 309 patients reported the occurrence of untreated attacks at baseline, and 182 patients reported untreated attacks at follow-up
(Table 2). When we compared the duration of untreated attacks across BMI groups, no statistical difference in the mean duration of attack among the three BMI groups was found ( $\mathrm{P}=0.408$ at baseline, $\mathrm{P}=0.530$ at follow-up), 
Table 2 Average duration of untreated attacks

\begin{tabular}{|c|c|c|c|c|}
\hline & $\begin{array}{l}\text { Under- } \\
\text { weight BMI }\end{array}$ & $\begin{array}{l}\text { Normal } \\
\text { BMI }\end{array}$ & $\begin{array}{l}\text { Over- } \\
\text { weight } \\
\text { BMI }\end{array}$ & Obese BMI \\
\hline \multicolumn{5}{|l|}{ Baseline } \\
\hline \multicolumn{5}{|c|}{ Average duration of attack (h) } \\
\hline$n$ & 12 & 150 & 106 & 41 \\
\hline Mean \pm SD $^{a}$ & $50.7 \pm 22.9$ & $40.5 \pm 32.4$ & $45.9 \pm 31.5$ & $44.4 \pm 35.5$ \\
\hline $\begin{array}{l}\text { Median } \\
\quad \text { (range) }\end{array}$ & $48.0(6-92)$ & $41.0(0-140)$ & $48.0(0-156)$ & $48.0(0-120)$ \\
\hline \multicolumn{5}{|l|}{ Follow-up } \\
\hline \multicolumn{5}{|c|}{ Average duration of attack (h) } \\
\hline$n$ & 11 & 76 & 70 & 25 \\
\hline Mean \pm SD $^{a}$ & $34.6 \pm 21.6$ & $39.7 \pm 31.1$ & $37.6 \pm 30.6$ & $44.2 \pm 29.9$ \\
\hline $\begin{array}{l}\text { Median } \\
\text { (range) }\end{array}$ & $36(0-72)$ & $37.5(0-144)$ & $28.7(0-120)$ & $48.0(0.3-120)$ \\
\hline
\end{tabular}

Average duration of untreated attacks corresponds to mean of average durations of untreated attacks at the skin, abdomen, larynx, and other sites $B M /$ body mass index; $S D$ standard deviation; $\mathrm{n}=$ the number of patients

a $P$ values comparing average duration of attack at baseline between patients with normal/overweight/obese $B M I: P=0.408$ at baseline; $P=0.530$ at follow-up. Results excluding data from the two reinjection outliers are presented in Additional file 1: Table S2

although mean attack duration at follow-up tended to be longer in the obese BMI group.

\section{Treatment characteristics}

Icatibant use was comparable among the BMI groups (Table 3). More than $70 \%$ of icatibant injections among all BMI groups were self-administered. Overall, 88.3, $83.8,83.2$, and $71.9 \%$ of attacks in patients with underweight, normal, overweight, and obese BMI, respectively, were treated with a single icatibant injection and without plasma-derived $\mathrm{C} 1$-INH rescue medication. Two patients (one with normal BMI, one with obese BMI) were previously identified as outliers because of an abnormally high rate of reinjections and rescue medication use [7]. Patient characteristics excluding the outliers are presented in Additional file 1: Table S1. When data from the two outliers were excluded, 88.3, 84.6, 83.2, and $82.0 \%$ of attacks in patients with underweight, normal, overweight, and obese BMI, respectively, were treated with a single icatibant injection (Additional file 1: Table S3). A single dose of plasma-derived C1-INH (pdC1-INH) was administered as rescue medication in 8.7, 7.7, 10.9, and $21.3 \%$ of attacks for patients with underweight, normal, overweight, and obese BMI, respectively $(P<0.0001)$. In most attacks that were treated with pdC1-INH rescue, pdC1-INH was administered following a single dose of icatibant. When data from the outliers were excluded, pdC1-INH use occurred in 8.7, 7.9, 10.9, and $12.0 \%$ of attacks for patients with underweight, normal, overweight, and obese $\mathrm{BMI}$, respectively $(\mathrm{P}=0.0232)$. Thus, there was a slight increase in the rate of $\mathrm{pdC} 1-\mathrm{INH}$ use with higher BMI.

\section{Treatment outcomes}

Overall, there was no difference among the BMI groups in time to treatment $(\mathrm{P}=0.468$; Fig. 3$)$. However, pairwise comparisons showed that time to treatment was shorter for patients with overweight BMI compared with patients with normal BMI $(P=0.007)$. There were significant differences overall among the BMI groups with respect to duration of attack and time to resolution ( $\mathrm{P}<0.001$ for both outcomes). Moreover, both outcomes were significantly shorter for patients with overweight and obese BMI compared with patients with normal BMI. Time to resolution was significantly extended in patients with overweight and obese BMI if they treated attacks $\geq 1$ or $\geq 2 \mathrm{~h}$ after attack onset compared with earlier treatment (Table 4). However, this impact on time to resolution was not observed in patients with normal BMI.

Multivariate regression analyses showed that patients with $\mathrm{BMI} \geq 25 \mathrm{~kg} / \mathrm{m}^{2}$ were more likely to treat attacks within $1 \mathrm{~h}$ than patients with $\mathrm{BMI}<25 \mathrm{~kg} / \mathrm{m}^{2}(\mathrm{P}<0.0295$; Table 5). Patients with a high frequency of attacks also were more likely to treat attacks early, and country also plays a role in time to treatment in the univariate analysis $(\mathrm{P}<0.0001)$, which was not confirmed in the multivariate analysis (Table 5). Time to resolution was more likely to be shorter for patients with higher BMI, and for attacks that were treated with $\mathrm{C} 1$-INH rescue medication or that affected the skin (Table 6).

\section{Adverse events (AEs)}

There was no difference in the rate of AEs between patients with underweight, normal, overweight, and obese BMI (Table 7). The most common treatment-related AEs across all other BMI groups were injection site reactions such as injection site pain (one report in one patient with overweight BMI) and injection site erythema (six reports in one patient with overweight BMI and one report in one patient with normal BMI). There were no injection site reactions in patients with obese BMI. There were no differences between the BMI groups with respect to the rate of vascular AEs. Two patients in the overweight BMI group reported a total of three serious AEs related to icatibant (gastritis and reflux esophagitis in one patient and angioedema in another patient).

\section{Discussion}

The results of our analysis of real-world data showed that the frequency and characteristics of C1-INHHAE attacks are generally similar across BMI groups. 
Table 3 Treatment of attacks

\begin{tabular}{|c|c|c|c|c|}
\hline & Underweight BMI & Normal BMI & Overweight BMI & Obese BMI \\
\hline \multicolumn{5}{|l|}{ Type of administration, $\mathrm{n}(\%)^{\mathrm{a}}$} \\
\hline $\mathrm{n}$ & 103 & 1261 & 792 & 415 \\
\hline $\mathrm{HCP}$ & $10(9.7)$ & $367(29.1)$ & $148(18.7)$ & $67(16.1)$ \\
\hline Self & $93(90.3)$ & $894(70.9)$ & $644(81.3)$ & $348(83.9)$ \\
\hline \multicolumn{5}{|l|}{ No. of icatibant injections per attack ${ }^{a}$} \\
\hline $\mathrm{n}$ & 103 & 1301 & 826 & 434 \\
\hline Mean $\pm S D$ & $1.0 \pm 0.2$ & $1.1 \pm 0.3$ & $1.1 \pm 0.3$ & $1.1 \pm 0.4$ \\
\hline Median (range) & $1(1-3)$ & $1(1-3)$ & $1(1-3)$ & $1(1-6)$ \\
\hline \multicolumn{5}{|c|}{ No. of icatibant injections per attack, n (\%) } \\
\hline$n$ & 103 & 1301 & 826 & 434 \\
\hline 1 & $91(88.3)$ & $1090(83.8)$ & $687(83.2)$ & $312(71.9)$ \\
\hline $1+\mathrm{C} 1-\mathrm{INH}$ rescue medication & $9(8.7)$ & $83(6.4)$ & $85(10.3)$ & $73(16.8)$ \\
\hline 2 & $2(1.9)$ & $112(8.6)$ & $48(5.8)$ & $24(5.6)$ \\
\hline $2+\mathrm{C} 1-\mathrm{INH}$ rescue medication & 0 & $8(0.6)$ & $5(0.6)$ & $22(5.1)$ \\
\hline 3 & $1(1.0)$ & $6(0.5)$ & $1(0.1)$ & $2(0.5)$ \\
\hline $3+\mathrm{C} 1-\mathrm{INH}$ rescue medication & 0 & $2(0.2)$ & 0 & 0 \\
\hline 6 & 0 & 0 & 0 & $1(0.2)^{b}$ \\
\hline \multicolumn{5}{|l|}{ C1-INH rescue medication, $\mathrm{n}(\%)$} \\
\hline $\mathrm{n}$ & 104 & 1314 & 829 & 450 \\
\hline No. of attacks used C1-INH rescue & $9(8.7)$ & $101(7.7)^{c}$ & $90(10.9)$ & $96(21.3)^{c, d}$ \\
\hline No. of patients used C1-INH rescue & 2 & 29 & 21 & 16 \\
\hline
\end{tabular}

BMI body mass index; C1-INHC1-inhibitor; HCP health care provider; SD standard deviation; $\mathrm{n}=$ number of attacks, excluding attacks with missing or unknown data

a Two patients (one normal BMI, one obese BMI) were found to be outliers because of an abnormally high rate of reinjections and rescue medication use. However, their data were included in this analysis

b One patient experienced an abdominal attack that lasted for 6 days; the patient was treated with one icatibant injection each day, for a total of six injections

c When data from the outlier patient were excluded, 47/393 (12.0\%) of attacks were treated with C1-INH. The other outlier patient did not use any rescue medication (Additional file 1: Table S3)

d One attack was treated with $\mathrm{C} 1-\mathrm{INH}$; however, the number of icatibant injections used was unknown

Interestingly, the rate of attacks according to site significantly differed by BMI group in that patients with high BMI reported fewer attacks on the abdomen and more attacks on the skin. The reason for the difference is unknown, but a relationship between BMI and mediators of angioedema or inflammation in the gut could be possible.

The results of our analysis of real-world observational data showed that treatment of C1-INH-HAE attacks with icatibant was successful regardless of BMI. The majority of attacks across BMI groups were treated with a single dose of icatibant and without the need for pdC1-INH rescue medication. Although there was a higher rate of pdC1-INH rescue medication use in patients with obese BMI (even when data from the two outlier patients were excluded), the difference between obese and other BMI groups was minimal. This suggests that overall, it is not necessary to adjust the administered dose of icatibant according to body weight.

Data from studies in healthy volunteers showed a significant correlation between body weight and the clearance and volume of distribution of icatibant, resulting in decreased systemic exposure for those with higher body weight [8]. This lower exposure could explain why there was an apparent increase in the rate of rescue medication use in patients with higher BMI. However, these studies were limited to volunteers with $\mathrm{BMI}<30 \mathrm{~kg} / \mathrm{m}^{2}$, thus effects in obese patients are unclear.

Patients with higher BMI were more likely to treat with icatibant within $1 \mathrm{~h}$ after the onset of an attack, and time to resolution and duration of attack were subsequently shorter in these patients. However, factors that impact BMI such as sex and age did not contribute to this outcome. The early treatment observed in overweight and obese BMI patients could be attributed to higher attack severity in these patients, or to the longer time required for attack resolution with delayed treatment in these groups. Earlier treatment and higher severity may suggest a more rapid onset of attacks in obese BMI patients, or conversely, a greater perception of symptoms leading to earlier treatment. 


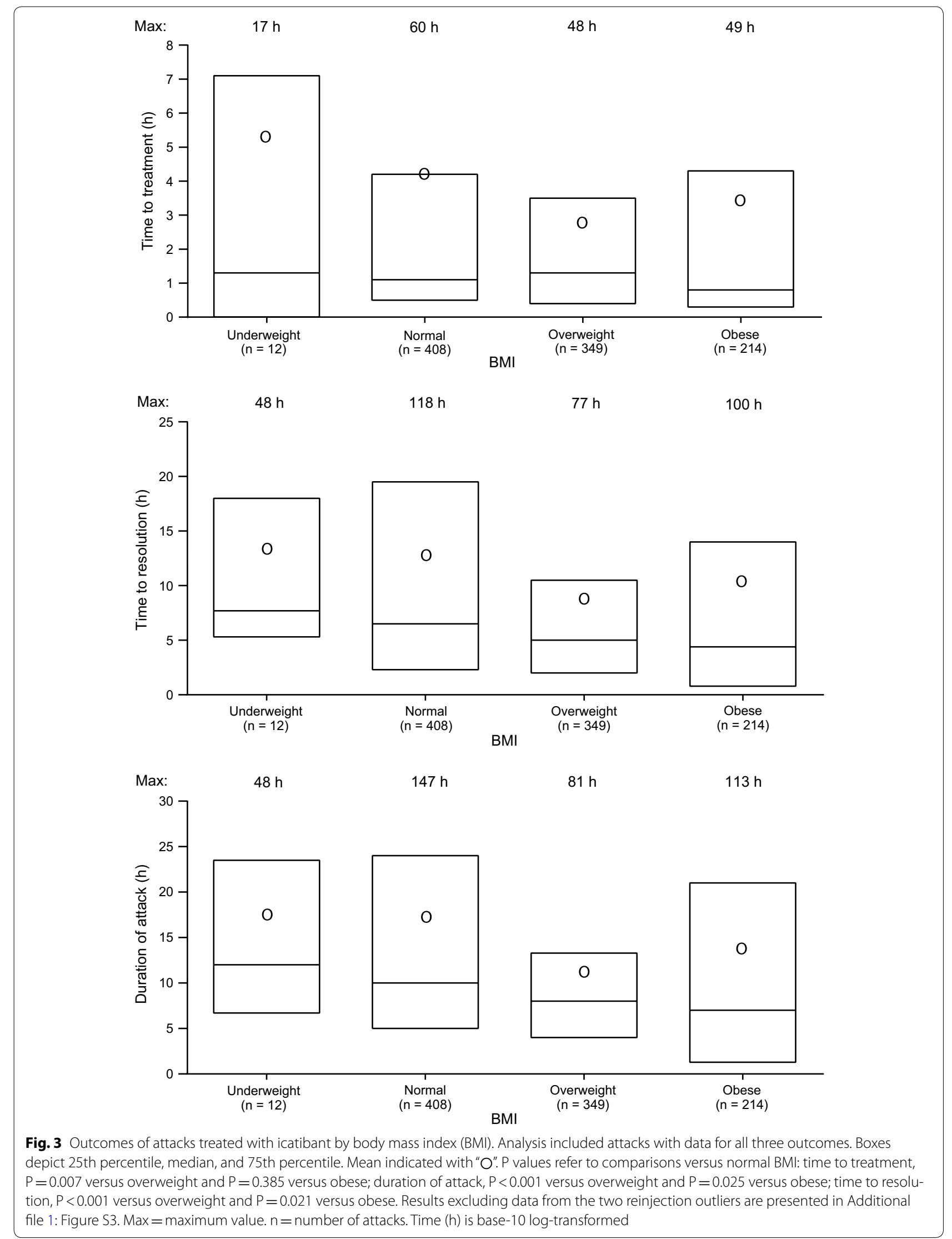


Table 4 Impact of time to treatment on mean time to resolution and duration of attack

\begin{tabular}{|c|c|c|c|c|c|c|c|c|}
\hline Time to treatment & n & Underweight BMI & $\mathbf{n}$ & Normal BMI & $\mathbf{n}$ & Overweight BMI & $\mathbf{n}$ & Obese BMI \\
\hline \multicolumn{9}{|c|}{ Mean \pm SD time to resolution } \\
\hline 0 to $<1 \mathrm{~h}$ & 6 & $15.6 \pm 16.7$ & 155 & $10.4 \pm 12.5$ & 148 & $7.9 \pm 11.0$ & 108 & $5.4 \pm 9.5$ \\
\hline$\geq 1 \mathrm{~h}$ & 6 & $10.1 \pm 8.4$ & 253 & $15.0 \pm 17.7$ & 201 & $9.9 \pm 12.4$ & 106 & $15.0 \pm 17.4$ \\
\hline P value & & n.a. & & 0.078 & & 0.001 & & $<0.001$ \\
\hline 0 to $<2 \mathrm{~h}$ & 6 & $15.6 \pm 16.7$ & 228 & $11.8 \pm 13.5$ & 193 & $8.4 \pm 12.0$ & 142 & $6.5 \pm 10.1$ \\
\hline$\geq 2 h$ & 6 & $10.1 \pm 8.4$ & 180 & $15.0 \pm 18.6$ & 156 & $9.8 \pm 11.6$ & 72 & $17.5 \pm 19.2$ \\
\hline P value & & n.a. & & 0.734 & & 0.011 & & $<0.001$ \\
\hline \multicolumn{9}{|c|}{ Mean $\pm S D$ duration of attack } \\
\hline 0 to $<1 \mathrm{~h}$ & 6 & $15.8 \pm 16.7$ & 155 & $10.7 \pm 12.5$ & 148 & $8.1 \pm 11.0$ & 108 & $5.6 \pm 9.5$ \\
\hline$\geq 1 h$ & 6 & $18.7 \pm 12.5$ & 253 & $21.8 \pm 22.0$ & 201 & $14.8 \pm 14.2$ & 106 & $22.4 \pm 20.8$ \\
\hline P value & & n.a. & & $<0.001$ & & $<0.001$ & & $<0.001$ \\
\hline 0 to $<2 \mathrm{~h}$ & 6 & $15.8 \pm 16.7$ & 228 & $12.3 \pm 13.7$ & 193 & $8.9 \pm 12.1$ & 142 & $6.9 \pm 10.2$ \\
\hline$\geq 2 h$ & 6 & $18.7 \pm 12.5$ & 180 & $24.2 \pm 23.8$ & 156 & $15.8 \pm 13.9$ & 72 & $27.7 \pm 22.1$ \\
\hline$P$ value & & n.a. & & $<0.001$ & & $<0.001$ & & $<0.001$ \\
\hline
\end{tabular}

Results excluding the two outlier patients are presented in Additional file 1: Table S4

$B M I$ body mass index; $n . a$. not applicable; statistical comparison was not conducted due to small sample sizes; $S D$ standard deviation; $\mathrm{n}=$ the number of attacks

Table 5 Evaluation of factors affecting time to treatment ${ }^{\mathrm{a}}$

\begin{tabular}{|c|c|c|c|}
\hline Effect (numerator) & Odds ratio & $95 \% \mathrm{Cl}$ & $P$ value \\
\hline \multicolumn{4}{|l|}{ Univariate analysis $^{b}$} \\
\hline $\begin{array}{l}\text { Attack frequency ( } \geq 10 \text { attacks/ } \\
\text { year) }\end{array}$ & 2.48 & - & $<0.001$ \\
\hline BMI $\left(\geq 25 \mathrm{~kg} / \mathrm{m}^{2}\right)$ & 1.77 & - & 0.012 \\
\hline Type of administration (HCP) & 0.55 & - & 0.067 \\
\hline Country & & & $<0.0001^{c}$ \\
\hline \multicolumn{4}{|l|}{ Multivariate analysis $^{\mathrm{d}}$} \\
\hline $\begin{array}{l}\text { Attack frequency ( } \geq 10 \text { attacks/ } \\
\text { year) })^{e}\end{array}$ & 2.89 & $1.36-6.14$ & 0.0056 \\
\hline $\operatorname{BMI}\left(\geq 25 \mathrm{~kg} / \mathrm{m}^{2}\right)^{\mathrm{e}}$ & 1.71 & $1.06-2.79$ & 0.0295 \\
\hline
\end{tabular}

$B M I$ body mass index; $C l$ confidence interval; $H C P$ health care provider

a Model of probability that time to treatment $<1 \mathrm{~h}$

${ }^{b}$ Only effects with $\mathrm{P}<0.2$ are shown. Complete results are presented in Additional file 1: Table S5

c Overall effect of country on time to treatment

d Only significant effects are shown

e Results were similar when data from the two reinjection outliers were excluded (Additional file 1:Table S6)

The results of the analysis presented here should be considered in the context that this was a retrospective analysis of real-world data rather than a randomized controlled clinical trial examining differences in the effectiveness of icatibant in patients with low or high BMI. Over half of the patients in this analysis had overweight or obese BMI, however this was similar to the overall distribution of BMI for adults in Europe [9]. Data collection was dependent on patient compliance with accurately
Table 6 Evaluation of factors affecting time to resolution ${ }^{\mathrm{a}}$

\begin{tabular}{|c|c|c|c|}
\hline Effect (numerator) & Odds ratio & $95 \% \mathrm{Cl}$ & P value \\
\hline \multicolumn{4}{|l|}{ Univariate analysis $^{\mathrm{b}}$} \\
\hline $\mathrm{BMI}\left(\geq 25 \mathrm{~kg} / \mathrm{m}^{2}\right)$ & 1.52 & - & 0.072 \\
\hline C1-INH rescue medication (yes) & 0.66 & - & 0.097 \\
\hline Affected site: skin (yes) & 0.74 & - & 0.118 \\
\hline Type of administration (HCP) & 1.49 & - & 0.133 \\
\hline Time to first injection ( $\geq 1 \mathrm{~h}$ ) & 0.78 & - & 0.142 \\
\hline Country & & & $0.019^{c}$ \\
\hline \multicolumn{4}{|l|}{ Multivariate analysis $^{d}$} \\
\hline $\mathrm{BMI}\left(\geq 25 \mathrm{~kg} / \mathrm{m}^{2}\right)$ & 4.46 & $2.24-8.89$ & $<0.0001$ \\
\hline C1-INH rescue medication (yes) & 0.31 & $0.19-0.50$ & $<0.0001$ \\
\hline Affected site: skin (yes) & 0.65 & $0.43-1.00$ & 0.049 \\
\hline
\end{tabular}

BMI body mass index; $C 1-I N H C 1$-inhibitor; $C l$ confidence interval; $H C P$ health care provider

${ }^{a}$ Model of probability that time to resolution $<5 \mathrm{~h}$

${ }^{b}$ Only effects with $\mathrm{P}<0.2$ are shown. Complete results are presented in Additional file 1: Table S7

c Overall effect of country on time to resolution

${ }^{d}$ Only significant effects are shown. Complete results excluding the two reinjection outliers are presented in Additional file 1: Table S8

documenting their attacks and treatments. In addition, the data collected on untreated attacks or attacks treated with other drugs were not as detailed as the data collected for icatibant-treated attacks. Thus, we were unable to fully evaluate the severity of disease in patients in the three BMI groups, as it is possible that not all attacks were accounted for. 
Table 7 AEs in all patients with C1-INH-HAE

\begin{tabular}{|c|c|c|c|c|}
\hline & Underweight BMI ( $n=18)$ & Normal BMI $(n=210)$ & Overweight BMI $(n=162)$ & Obese BMI $(n=73)$ \\
\hline No. of patients, no. of events & 3,3 & 48,101 & 33,91 & 19,53 \\
\hline $\begin{array}{l}\text { AEs related to icatibant (no. of patients, no. } \\
\text { of events) }\end{array}$ & 0,0 & 7,24 & 6,29 & 2,5 \\
\hline $\begin{array}{l}\text { General disorders and administration site } \\
\text { conditions }\end{array}$ & 0,0 & 5,9 & 3,11 & 1,1 \\
\hline Vascular disorders & 0,0 & 3,5 & 3,4 & 1,3 \\
\hline Skin and subcutaneous tissue disorders & 0,0 & 0,0 & 2,2 & 1,1 \\
\hline Gastrointestinal disorders & 0,0 & 2,2 & 1,3 & 0,0 \\
\hline Nervous system disorders & 0,0 & 1,1 & 1,2 & 0,0 \\
\hline Investigations & 0,0 & 2,5 & 0,0 & 0,0 \\
\hline Serious AEs (no. of patients, no. of events) & 0,0 & 20,28 & 16,32 & 11,30 \\
\hline $\begin{array}{l}\text { Serious AEs related to icatibant and (no. of } \\
\text { patients, no. of events) })^{b}\end{array}$ & 0,0 & 0,0 & 2,3 & 0,0 \\
\hline \multicolumn{5}{|l|}{ Skin and subcutaneous tissue disorders } \\
\hline Angioedema & 0,0 & 0,0 & 1,1 & 0,0 \\
\hline \multicolumn{5}{|l|}{ Gastrointestinal disorders } \\
\hline Gastritis & 0,0 & 0,0 & 1,1 & 0,0 \\
\hline Reflux esophagitis & 0,0 & 0,0 & 1,1 & 0,0 \\
\hline
\end{tabular}

A missing relationship to icatibant was considered related to icatibant

$A E$ adverse event; $B M I$ body mass index; $C 1-I N H-H A E$ hereditary angioedema due to $C 1$-inhibitor deficiency; $\mathrm{n}=$ number of patients

a Listed by medical dictionary for regulatory activities system organ class. Only AEs that were reported in $\geq 2$ patients are presented

b Listed by medical dictionary for regulatory activities system organ class and preferred term

\section{Conclusions}

In conclusion, icatibant was well tolerated and used successfully to treat attacks in patients with overweight and obese BMI.

\section{Additional file}

Additional file 1. Effectiveness of icatibant for treatment of hereditary angioedema attacks is not affected by body weight: findings from the Icatibant Outcome Survey, a cohort observational study.

\section{Abbreviations}

AE: adverse event; BMI: body mass index; C1-INH: C1-inhibitor; C1-INH-HAE: HAE due to C1-inhibitor deficiency; Cl: confidence interval; HCP: health care professional; IOS: Icatibant Outcome Survey; n.a.: not applicable; OR: odds ratio; SD: standard deviation.

\section{Authors' contributions}

$T C, A Z, W A, M M, H J L, L B$ and IA contributed to study conception and design, data acquisition, analysis and interpretation, drafting the manuscript, and critical content revisions. All authors read and approved the final manuscript. Although employees of the sponsor were involved in the design, collection, analysis, interpretation, and fact-checking of information, the content of this manuscript, the interpretation of the data, and the decision to submit the manuscript for publication in Clinical and Translational Allergy was made by the authors independently.

\section{Author details}

${ }^{1}$ Allergy Department, Hospital La Paz Institute for Health Research (IdiPaz), Biomedical Research Network on Rare Diseases (CIBERER, U754), Madrid, Spain. ${ }^{2}$ Department of Biomedical and Clinical Sciences Luigi Sacco, University of Milan, ASST Fatebenefratelli Sacco, Milan, Italy. ${ }^{3}$ Department of Dermatology and Venerology, Medical University of Graz, Graz, Austria. ${ }^{4}$ Department of Dermatology and Allergy, Charité - Universitätsmedizin Berlin, Berlin, Germany. ${ }^{5}$ Department of Immunology, Barts Health NHS Trust, London, UK. ${ }^{6}$ National Reference Centre for Angioedema, Internal Medicine, Grenoble University Hospital, Grenoble, France. ${ }^{7}$ Shire, Zug, Switzerland.

${ }^{8}$ Servicio de Alergia, Hospital Universitario La Paz, Paseo de la Castellana 261 28046 Madrid, Spain. ${ }^{9}$ Present Address: Addenbrooke's Hospital, Cambridge University Hospitals NHS Foundation Trust, Cambridge, UK.

\section{Acknowledgements}

Statistical analyses were conducted by Amandine Perrin, MSc, and additional support was provided by Jaco Botha, MSc, and Christelle Pommie, MSc, of Shire. Under the direction of the authors, Shirley Teng, PhD, CMPP, of Excel Scientific Solutions, provided writing assistance for this publication. Editorial assistance in formatting, proofreading, copy-editing, and fact-checking also was provided by Excel Scientific Solutions. Funding for writing and editorial assistance was provided by Shire Human Genetic Therapies, Lexington, MA, USA.

IOS investigators: Austria: W. Aberer, M. Wiednig; Brazil: A. Grumach; Denmark: A. Bygum; France: C. Blanchard Delaunay, I. Boccon-Gibod, L. Bouillet, B. Coppere, O. Fain, B. Goichot, A. Gompel, S. Guez, P.Y. Jeandel, G. Kanny, D. Launay, H. Maillard, L. Martin, A. Masseau, Y. Ollivier, A. Sobel; Germany: J. Arnolds, E. Aygören-Pürsün, M. Baş, M. Bauer, K. Bork, I. MartinezSaguer, M. Maurer; Greece: E. Papadopoulou-Alataki, F. Psarros; Israel: Y. Graif, S. Kivity, A. Reshef, E. Toubi; Italy: F. Arcoleo, M. Bova, M. Cicardi, P. Manconi, G. Marone, V. Montinaro, A. Zanichelli; Spain: M.L. Baeza, T. Caballero, R. Cabañas, M. Guilarte, D. Hernandez, C. Hernando de Larramendi, R. Lleonart, T. Lobera, L. Marques, B. Saenz de San Pedro; Sweden: J. Björkander; United Kingdom: C. Bethune, T. Garcez Pereira, M. Helbert, H.J. Longhurst.

\section{Competing interests}

T.C. has received speaker fees from CSL Behring, GlaxoSmithKline, MSD, Novartis, and Shire; consultancy fees from BioCryst, CSL Behring, Novartis, Shire, and Sobi; funding for travel and meeting attendance from CSL Behring, Novartis, and Shire; and has participated in clinical trials/registries for BioCryst, CSL Behring, Novartis, Pharming, and Shire. She is a researcher for the IdiPaz 
program promoting research activities. A.Z. has received speaker/consultancy fees from CSL Behring, Shire, and Sobi. W.A. has acted as a medical advisor and speaker for BioCryst, CSL Behring, Pharming, and Shire; and has received funding to attend conferences/educational events and donations to his departmental fund from and participated in clinical trials for Shire. M.M. has received research grant support and/or speaker/consultancy fees from BioCryst, CSL Behring, Dyax, Pharming, and Shire. H.J.L. has received research grant support and/or speaker/consultancy fees from BioCryst, CSL Behring, Dyax, Shire, and Sobi. L.B. has received honoraria from BioCryst, CSL Behring, Novartis, Pharming, and Shire; and her institute has received research funding from CSL Behring, GlaxoSmithKline, Novartis, Roche, and Shire. I.A. is a full-time employee of Shire, Zug, Switzerland.

\section{Availability of data and materials}

The datasets generated during the current study are not publicly available because the data from IOS reside in a proprietary database maintained by Shire, but data are available from the corresponding author on reasonable request and with permission of Shire.

\section{Ethics approval and consent to participate}

IOS is conducted in multiple sites across 11 countries in accordance with the Declaration of Helsinki and the International Conference on Harmonisation Good Clinical Practice guidelines. All sites obtained approval from local ethics committees and/or health authorities (where applicable), and all patients provided written informed consent before the initiation of data collection. Consent from parents or a legal representative was obtained for patients who were younger than 18 years of age at the time of enrollment.

\section{Funding}

IOS is sponsored by Shire Human Genetic Therapies, Lexington, MA, USA.

\section{Publisher's Note}

Springer Nature remains neutral with regard to jurisdictional claims in published maps and institutional affiliations.

Received: 19 December 2017 Accepted: 28 February 2018

Published online: 23 March 2018

\section{References}

1. Cicardi M, Aberer W, Banerji A, Bas M, Bernstein JA, Bork K, and on behalf of HAWK, under the patronage of EAACI (European Academy of Allergy and Clinical Immunology), et al. Classification, diagnosis, and approach to treatment for angioedema: consensus report from the Hereditary Angioedema International Working Group. Allergy. 2014;69:602-16.

2. Longhurst $\mathrm{H}$, Cicardi M. Hereditary angio-oedema. Lancet. 2012;379:474-81.

3. Craig T, Aygören-Pürsün E, Bork K, Bowen T, Boysen H, Farkas H, et al. WAO guideline for the management of hereditary angioedema. World Allergy Organ J. 2012;5:182-99.

4. Cicardi M, Banerji A, Bracho F, Malbrán A, Rosenkranz B, Riedl M, et al. Icatibant, a new bradykinin-receptor antagonist, in hereditary angioedema. N Engl J Med. 2010;363:532-41.

5. Lumry WR, Li HH, Levy RJ, Potter PC, Farkas H, Moldovan D, et al. Randomized placebo-controlled trial of the bradykinin $B_{2}$ receptor antagonist icatibant for the treatment of acute attacks of hereditary angioedema: the FAST-3 trial. Ann Allergy Asthma Immunol. 2011;107(529-37):e2.

6. Maurer M, Aberer W, Bouillet L, Caballero T, Fabien V, Kanny G, on behalf of IOS Investigators, et al. Hereditary angioedema attacks resolve faster and are shorter after early icatibant treatment. PLOS ONE. 2013;8:e53773.

7. Longhurst HJ, Aberer W, Bouillet L, Caballero T, Fabien V, Zanichelli A, et al. Analysis of characteristics associated with reinjection of icatibant: results from the Icatibant Outcome Survey. Allergy Asthma Proc. 2015;36:399-406.

8. Firazyr [package insert]. Shire, Lexington, MA; 2015. https://www.accessdata.fda.gov/drugsatfda_docs/label/2015/022150s007/bl.pdf. Accessed 30 Nov 2017.

9. Eurostat. European Health Interview Survey: Almost 1 adult in 6 in the EU is considered obese. http://ec.europa.eu/eurostat/ documents/2995521/7700898/3-20102016-BP-EN.pdf/c26b037b-d5f34c05-89c1-00bf0b98d646. Accessed 30 Nov 2017.

\section{Submit your next manuscript to BioMed Central and we will help you at every step:}

- We accept pre-submission inquiries

- Our selector tool helps you to find the most relevant journal

- We provide round the clock customer support

- Convenient online submission

- Thorough peer review

- Inclusion in PubMed and all major indexing services

- Maximum visibility for your research

Submit your manuscript at www.biomedcentral.com/submit
C BioMed Central 